\title{
Parainfectious vasculitis due to Pneumococcal meningitis following traumatic CSF rhinorrhoea resulting in cerebellar infarction
}

\author{
Ummer Karadan', Robin George Manappallil2, Manoj Bhaskaran³, \\ Anoop Chandran Vazhipokkil ${ }^{4}$, Ivin Panakkel Zacharia ${ }^{5}$ \\ ${ }^{1}$ Senior Consultant and Interventional Neurologist, Department of Neurology, Baby Memorial Hospital, Calicut, Kerala, \\ India, ${ }^{2}$ Consultant, Department of Internal Medicine, Baby Memorial Hospital, Calicut, Kerala, India, ${ }^{3}$ Senior Consultant, \\ ${ }^{4}$ Consultant, Department of Otorhinolaryngology, Baby Memorial Hospital, Calicut, Kerala, India, ${ }^{5}$ Resident, Department \\ of Neurology, Baby Memorial Hospital, Calicut, Kerala, India
}

A B S T R A C T

Parainfectious vasculitis is a rare life threatening complication of Streptococcus pneumoniae (S.pneumoniae) meningitis. There is a $19 \%$ risk of developing meningitis in the patients with cerebrospinal fluid (CSF) rhinorrhoea. The patient being reported developed CSF rhinorrhoea due to traumatic fracture of cribriform plate, followed by pneumococcal meningitis and parainfectious vasculitis resulting in cerebellar infarction.

Key words: Streptococcus pneumonia; Pneumococcal meningitis; Vasculitis; CSF rhinorrhoea; Cerebellar infarction; Steroids

\section{Access this article online}

Website:

http://nepjol.info/index.php/AJMS DOI: $10.3126 /$ ajms.v11i4.29178

E-ISSN: 2091-0576

P-ISSN: 2467-9100

Copyright (c) 2020 Asian Journal of Medical Sciences

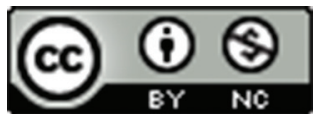

This work is licensed under a Creative Commons Attribution-NonCommercial 4.0 International License.

\section{INTRODUCTION}

Bacterial meningitis is a life threatening condition and has a high risk of developing neurological sequelae. Parainfectious vasculitis resulting in brain infarction is an uncommon complication; holding a high mortality rate. The treatment of this condition remains uncertain. ${ }^{1-3}$ The neurological complications associated with pneumococcal meningitis include seizures, cerebral edema, hydrocephalus, hearing loss, and ischemic or haemorrhagic brain damage. ${ }^{4}$ Patients with CSF rhinorrhoea have a 19\% higher risk of developing meningitis. ${ }^{5}$

\section{CASE PRESENTATION}

A 64 year old diabetic lady (on glimepiride $1 \mathrm{mg}$ once daily and metformin $500 \mathrm{mg}$ twice daily) was brought with history of fever and projectile vomiting (2 to 3 episodes) since morning, which was followed by altered sensorium. The previous day evening, she had hit her head hard against a door, following which she had headache and clear watery nasal discharge. There was no loss of consciousness or seizure. She took oral paracetamol $(500 \mathrm{mg})$ and levocetrizine ( $5 \mathrm{mg}$ ) as self-medication, but there was no relief of symptoms. 
On examination, she was conscious, disoriented and febrile $\left(101^{\circ} \mathrm{F}\right)$. Her pulse rate was $110 /$ minute, blood pressure $140 / 80 \mathrm{mmHg}$ and respiratory rate $22 /$ minute (saturation 95\% in room air). There were no skin rashes. Neck stiffness was present. Other systemic examinations were normal. Her blood investigations showed leucocytosis (14400 cells/cumm, with neutrophils $90 \%$, lymphocytes $10 \%$ ). Her renal and liver parameters, electrolytes, prothrombin time and urine routine were normal. Smear for malarial parasite, viral markers (HIV, HBsAg, anti HCV) and Weil Felix tests were negative. Computed tomography (CT) of brain, echocardiography and chest Xray were also normal. Her CSF was turbid, with WBC 10560 cells/cumm (neutrophils 93\%, lymphocytes 3\%, eosinophils 4\%), RBC 92 cells/cumm, protein $296 \mathrm{mg} / \mathrm{dL}$, glucose $18 \mathrm{mg} / \mathrm{dL}$ (random blood glucose 191). CSF Gram stain showed Gram positive cocci, and acid fast bacillus stain and real time polymerase chain reaction for tuberculosis were negative. In view of bacterial meningitis, she was started on intravenous ceftriaxone (2 gram q12h) and intravenous vancomycin (30 mg/kg q12h), along with intravenous dexamethasone (4 mg q6h, with first dose given 20 minutes prior to antibiotic therapy). Blood glucose levels were controlled with insulin therapy. Other supportive medications like intravenous fluids, pantoprazole and paracetamol were also given.

By day 3, she became oriented. Her CSF and blood culture grew Streptococcus pneumoniae (S.pneumoniae). Ceftriaxone was continued (as it was sensitive), and vancomycin (intermediate sensitive) was stopped. Repeat CSF analysis (on day 3) was normal, and the frequency of dexamethasone was reduced to $\mathrm{q} 8 \mathrm{~h}$. The following day, she developed left upper limb ataxia and vertigo. Magnetic resonance (MR) imaging of the brain showed left cerebellar infarct (Figure 1) and MR angiography was

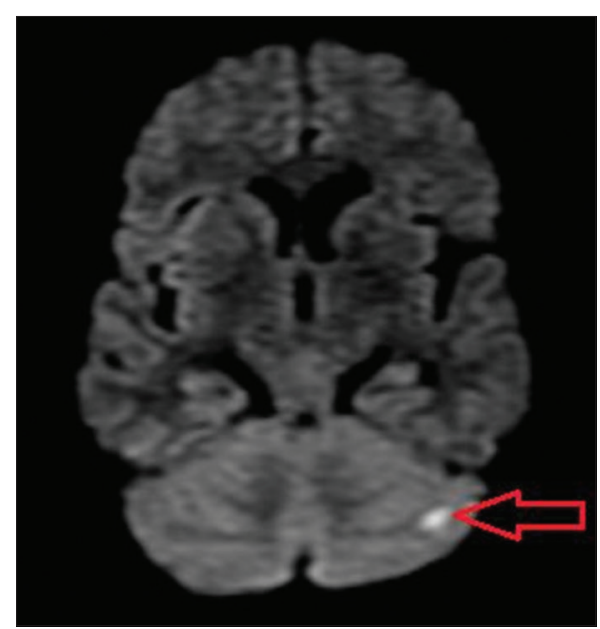

Figure 1: Diffusion weighted image (DWI) of brain showing small restricted diffusion in the left cerebellar hemisphere suggestive of acute infarction normal. Antinuclear antibody profile was negative. In view of parainfectious vasculitic infarct, her dexamethasone dose and frequency was increased to $10 \mathrm{mg} \mathrm{q} 6 \mathrm{~h}$, along with oral aspirin (150 mg once daily) and atorvastatin (40 mg once daily). By day 7 , she was asymptomatic. Her repeat CSF culture (sent on day 4) was sterile. Dexamethasone $10 \mathrm{mg}$ q6h was continued for total of 4 days, and then changed to oral prednisolone $(1 \mathrm{mg} / \mathrm{kg} / \mathrm{day})$. Her nasal discharge sample tested positive for beta- 2 transferrin and CT cisternography showed a defect in the right lateral lamella $(8 \times 5 \mathrm{~mm})$ and cribriform plate $(1.5 \mathrm{~mm})$ with active contrast leak adjacent to the lateral lamella (Figure 2). After completing 14 days of ceftriaxone therapy, she was discharged on insulin, aspirin ( $75 \mathrm{mg}$ once daily), atorvastatin (40 $\mathrm{mg}$ once daily) and tapering doses of prednisolone. On review after 2 weeks, she continued to be asymptomatic, except for mild watery nasal discharge. Aspirin was stopped for 7 days, and she was posted for transnasal endoscopic repair of right cribriform plate under general anaesthesia. The repair was done with right fascia lata and muscle graft was reinforced with fat and gel foam. Her post-operative period was uneventful. She was asked to continue insulin, aspirin and atorvastatin, along with oral amoxicillin (500 mg thrice daily for 5 days).

\section{DISCUSSION}

S.pneumoniae is a common pathogen for bacterial meningitis among children in India. ${ }^{6}$ Pneumococcal meningitis can result in intracranial and systemic complications. The neurological complications were diffuse brain oedema, hydrocephalus, vasculitis associated spontaneous intracranial haemorrhages (subarachnoid and intracerebral bleedings), intracerebral haemorrhage due to sinus thrombosis, acute spinal cord dysfunction

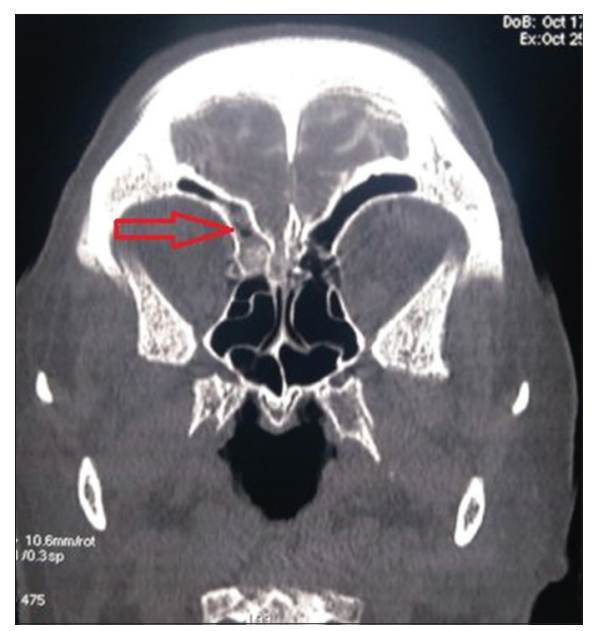

Figure 2: CT cisternography showing a defect in the right lateral lamella and cribriform plate with active contrast leak adjacent to the lateral lamella 
due to myelitis and hearing loss. Systemic complications were the main cause of death in elderly, while in youngsters it was cerebral complications. ${ }^{4}$ Antimicrobial therapy can be initiated with cephalosporin (ceftriaxone, cefotaxime, cefepime) and vancomycin, which can be modified later based on antibiotic sensitivity reports. The duration of antibiotic therapy is for 2 weeks. A repeat CSF analysis should be done 24 to 36 hours after the initiation of antibiotics in order to document sterilization of CSF; and a failure to achieve this indicates antibiotic resistance. The administration of antibiotics releases bacterial cell wall components, thereby leading to the production of inflammatory cytokines (interleukin $1 \beta$ and tumour necrosis factor $\alpha$ ) in the subarachnoid space. Steroids like dexamethasone inhibit the synthesis of these inflammatory cytokines and stabilises the blood brain barrier. Dexamethasone should be given about 20 minutes prior to antibiotics because steroids cannot alter the production of these inflammatory cytokines once it has been induced. The adjuvant use of dexamethasone has shown beneficial effects in terms of death and prevention of neurological complications, especially in pneumococcal meningitis. The only concerns include the decreased penetration of vancomycin into the CSF, and the possibilities of hippocampal cell injury and decreased learning capacity ${ }^{7}$

CSF rhinorrhoea is described as discharge of CSF from the nose due to an abnormal path between the subarachnoid space and the nasal sinus cavities. Trauma to the face and head may cause a naso-orbito-ethmoidal fracture and damage to the cribriform plate, resulting in CSF rhinorrhoea. Other causes include birth defects, increased intracranial pressure or nasal sinus surgery complications. These patients present with rhinorrhoea, headache, anosmia and nasal congestion. Beta 2 transferrin assay, nasal endoscopy and imaging modalities like $\mathrm{CT}$ and MRI scan help to establish the diagnosis. As mentioned earlier, patients with CSF rhinorrhoea have a higher risk of developing meningitis, and endoscopic closure is the mainstay of treatment. ${ }^{5}$

Brain infarction is an uncommon complication of meningitis caused due to vasculitis. The probable mechanism is due to vascular inflammation by the inflammatory cytokines, disrupting the blood-brain barrier following antibioticinduced autolysis. The administration of dexamethasone prior to antibiotics helps to reduce such complications. Only a handful of cases of brain vasculitis due to meningitis have been reported. ${ }^{8-10}$ Our patient had a traumatic CSF rhinorrhoea leading to pneumococcal meningitis. She was given dexamethasone prior to antibiotic therapy, but in a lower dose in view of decreased vancomycin penetration into the CSF. However, she developed vasculitis induced cerebellar infarction. She recovered on increasing the dose of dexamethasone. Cerebellar vasculitic infarction is a rare condition, and has been reported with systemic lupus erythematosus. ${ }^{11}$ To the best of our knowledge, parainfectious vasculitis due pneumococcal meningitis resulting in cerebellar infarction has not been reported yet. The probable reason behind our patient developing parainfectious vasculitis must be the early under dosing of dexamethasone.

Pneumococcal infection is a vaccine-preventable disease. Currently, two vaccines are available: pneumococcal conjugate vaccine (PCV13) and pneumococcal polysaccharide vaccine (PPSV23). All adults above 65 years of age should receive 1 dose of PCV13 followed by 1 dose of PPSV23 after 1 year. If 2 or more doses of PPSV23 are indicated, then each dose should be given an interval of at least 5 years. Adults 19 years of age and above with immunocompromising conditions, anatomical or functional asplenia, CSF leak, cochlear implants, chronic renal failure, nephrotic syndrome, leukemia, lymphoma, Hodgkin disease, generalized malignancy or taking immunosuppressive drugs should receive 1 dose of PCV13 followed by PPSV23 after 8 weeks and 5 years. ${ }^{12}$

\section{CONCLUSION}

Patients with CSF rhinorrhoea are at risk of developing meningitis, especially due to S.pneumoniae. These patients should be given dexamethasone, prior to and along with antibiotics, in order to prevent neurological complications, which can be life threatening. High risk patients should receive pneumococcal vaccine for disease prevention.

\section{REFERENCES}

1. Pugin D, Copin JC, Goodyear MC, Landis T and Gasche Y. Persisting vasculitis after pneumococcal meningitis. Neurocritical Care 2006; 4: 237-240.

https://doi.org/10.1385/NCC:4:3:237

2. Durand ML, Calderwood SB, Weber DJ, Miller SI, Southwick FS, Caviness Jr VS, et al. Acute bacterial meningitis in adults. A review of 493 episodes. N Engl J Med 1993;328(1):21-28.

https://doi.org/10.1056/NEJM199301073280104

3. Pfister HW, Feiden $W$ and Einhäupl KM. Spectrum of complications during bacterial meningitis in adults-results of a prospective clinical study. Arch Neurol 1993; 50:575-581.

https://doi.org/10.1001/archneur.1993.00540060015010

4. Kastenbauer $\mathrm{S}$ and Pfister HW. Pneumococcal meningitis in adults: spectrum of complications and prognostic factors in a series of 87 cases. Brain 2003; 126: 1015-1025. https://doi.org/10.1093/brain/awg113

5. Daudia A, Biswas D and Jones NS. Risk of meningitis with cerebrospinal fluid rhinorrhea. Ann Otol Rhinol Laryngol 2007; 116(12):902-905.

https://doi.org/10.1177/000348940711601206 
6. Jayaraman $Y, \quad$ Veeraraghavan B, Chethrapilly Purushothaman GK, Sukumar B, Kangusamy B, Kapoor AN, et al. Burden of bacterial meningitis in India: Preliminary data from a hospital based sentinel surveillance network. PLoS One 2018; 13(5):e0197198.

https://doi.org/10.1371/journal.pone.0197198

7. Roos KL and Tyler KL. Meningitis, Encephalitis, Brain Abscess and Empyema. In: Kasper, Fauci, Hauser, Longo, Jameson, Loscalzo (ed). Harrison's Principles of Internal Medicine. 19th ed. McGraw Hill education. pp. 883-906.

8. Khedher A, Sma N, Slama D, Fraj N Hachfi W and Boussarsas M. Cerebral vasculitis complicationg pneumococcal meningitis. EJCRIM 2018;5:

https://doi.org/10.12890/2018_000819
9. Poil AR, Shaukat A and Kumar D. Pneumococcal Meningitis Complicated by Cerebral Vasculitis, Abscess, Hydrocephalus, and Hearing Loss. Case Rep Infect Dis. 2018;2018:8528023. https://doi.org/10.1155/2018/8528023

10. Pugin D, Copin JC, Goodyear MC, Landis T and Gasche Y. Persisting vasculitis after pneumococcal meningitis. Neurocrit Care 2006;4:237-240. https://doi.org/10.1385/NCC:4:3:237

11. Kim YS, Park BS, Baek W and Kim SH. Massive vasculitic cerebellar infarction in patient with systemic lupus erythematosus. Neurol India 2012; 60:106-108. https://doi.org/10.4103/0028-3886.93603

12. Recommended Adult Immunization Schedule for ages 19 years or older, United States, 2020

Authors Contribution:

UK- Revision of manuscript and treating Neurologist; RGM- Concept and design, manuscript preparation, revision of manuscript and treating Physician;

MB- Revision of manuscript and treating Otorhinolaryngolist; ACV- Revision of manuscript and treating Otorhinolaryngolist; IPZ- Resident in-charge.

Orcid ID:

Dr. Robin George Manappallil- (은 http://orcid.org/0000-0003-3973-6800

Source of support: None, Conflicts of Interest: None 